\title{
The Prevalence of Hyponatremia in Pulmonary Tuberculosis Patients, a Tertiary Care Hospital Experience from Pakistan
}

\author{
Afshan Nisar' ${ }^{1}$ Amanullah Lail2, Darkhshan Nisar ${ }^{3}$, Syed Abdul Waheed1', Nausheen Saifullah'1, \\ Ghulamullah Lail ${ }^{4}$
}

${ }^{1}$ Department of Chest Medicine, Jinnah Postgraduate Medical Centre, Karachi, Pakistan

${ }^{2}$ Department of Pediatrics, Dow University Hospital, Karachi, Pakistan

${ }^{3}$ Department of Pharmacy (Pharmacology), Hamdard University Hospital, Karachi, Pakistan

${ }^{4}$ Department of Medicine and Allied, Jinnah Medical and Dental College, Karachi, Pakistan

Email: ga.lail@hotmail.com

How to cite this paper: Nisar, A., Lail, A., Nisar, D., Waheed, S.A., Saifullah, N. and Lail, G. (2019) The Prevalence of Hyponatremia in Pulmonary Tuberculosis Patients, a Tertiary Care Hospital Experience from Pakistan. Journal of Tuberculosis Research, 7, 259-266.

https://doi.org/10.4236/jtr.2019.74026

Received: July 25, 2019

Accepted: December 28, 2019

Published: December 31, 2019

Copyright $\odot 2019$ by author(s) and Scientific Research Publishing Inc. This work is licensed under the Creative Commons Attribution International License (CC BY 4.0).

http://creativecommons.org/licenses/by/4.0/

\begin{abstract}
Introduction: Tuberculosis (TB) is one of the major public health problems in Pakistan. Our country ranks fifth in tuberculosis high-burden countries worldwide. Hyponatremia is considered as one of the most common and important electrolyte abnormality in Pulmonary TB (PTB) patients. This study will show the prevalence of hyponatremia in PTB in our population. Objective: To evaluate the prevalence of hyponatremia in pulmonary tuberculosis patients. Study Design: Cross-sectional, descriptive study at Jinnah postgraduate medical centre Karachi from August 2017 to August 2018. Material and Methods: In this cross-sectional study, all patients with TB admitted in chest ward were enrolled. Patients having tuberculous meningitis, syndrome of inappropriate Ant diuretic hormone (SIADH), Renal failure, pneumonia, Cirrhosis taking medicines (diuretics, ACEI, and ARBs) were excluded. A pre-designed questionnaire was used to assess hyponatremia and its potential causes other than TB. Chi-square or Fischer exact test was used to identify factors associated with hyponatremia. Results: Ninety-six patients with mean age were $40.14 \pm 13.02$ years (ranging 18 - 65 years). Predominantly, patients were females 50 (52.08\%). Overall Serum Na, Mean \pm SD was $130.53 \pm 6.99$ (Ranging $110-146$ ). Sixty one patients $(63.5 \%)$ were younger than 40 years. Forty patients $(41.66 \%)$ were smokers: $16(16.7 \%)$ had diabetes mellitus (DM), and 15 (15.6\%) had hypertension. Sixty-nine (71.87\%) patients had hyponatremia of which $45(73.77 \%)$ were less than 40 years $(\mathrm{p}=$ 0.375). Diabetes mellitus, female gender, smoking, hypertension and duration of disease were not associated with increased risk of hyponatremia having $\mathrm{P}$ Values: $\mathrm{p}=0.082, \mathrm{p}=0.39, \mathrm{p}=0.57, \mathrm{p}=0.20$ and $\mathrm{p}=0.45$ respectively. Con-
\end{abstract}


clusion: Hyponatremia is associated with tuberculosis and is more common with diabetes, hypertension, smoking and young age.

\section{Keywords}

Hyponatremia, Tuberculosis, Electrolyte Imbalance, Tuberculosis Complications

\section{Introduction}

Tuberculosis (TB) is caused by bacteria (Mycobacterium tuberculosis) that most often affect the lungs. Tuberculosis is curable and preventable. TB occurs in every part of the world. In 2015, the largest number of new TB cases occurred in Asia, with $61 \%$ of new cases, followed by Africa, with $26 \%$ of new cases [1] [2].

Tuberculosis (TB) is one of the major public health problems in Pakistan. Pakistan ranks fifth amongst TB high-burden countries worldwide. It accounts for $61 \%$ of the TB burden in the WHO Eastern Mediterranean Region [2].

Pakistan is also estimated to have the fourth highest prevalence of multidrug-resistant TB (MDR-TB) globally. Tuberculosis (TB) is one of the top 10 causes of death worldwide. In 2015, 10.4 million people fell ill with TB and 1.8 million died from the disease (including 0.4 million among people with HIV). Over $95 \%$ of TB deaths occur in low- and middle-income countries. Prevalence of PTB with hyponatremia is around $51 \%$. Diabetes mellitus (DM) is currently known to be one of the risk factors for pulmonary tuberculosis [2] [3].

Common symptoms of active lung TB are cough with sputum and blood at times, chest pains, weakness, weight loss, fever and night sweats. Many countries still rely on a long-used method called sputum smear microscopy to diagnose TB. Microscopy detects only half the number of TB cases and cannot detect drug-resistance. The use of the rapid test Xpert MTB/RIF ${ }^{\oplus}$ has expanded substantially since 2010 . The test simultaneously detects TB and resistance to rifampicin, the most important TB medicine. Diagnosis can be made within 2 hours and the test is now recommended by WHO as the initial diagnostic test in all persons with signs and symptoms of TB [2] [3] [4]. TB is a treatable and curable disease. Active, drug-susceptible TB disease is treated with a standard 6-month course of 4 antimicrobial drugs that are provided with information, supervision and support to the patient by a health worker or trained volunteer. The WHO's ambitious End TB Strategy approved by all countries targets to reduce TB deaths by $90 \%$ in 2030 with intermediate milestones of reduction by $35 \%$ in 2020 and $75 \%$ in 2025 [5].

Various complications have been reported along with PTB. Pulmonary TB is associated with various long term lung complications including lung scarring (fibrosis), bronchiectasis, chronic pulmonary aspergillosis (CPA), air way stenosis and Chronic Obstructive Pulmonary Disease (COPD) [6]. The subclinical 
electrolyte imbalances are customary in cases with PTB. Hyponatremia is considered as one of the most common and important electrolyte abnormalities it must be considered in all seriously ill hospitalized patients [7] [8]. Hyponatremia is defined as depletion in the serum sodium $(\mathrm{Na})$ concentration to a level below $136 \mathrm{mmol} / \mathrm{l}$ and severe hyponatremia defined as serum sodium concentration lesser than $115 \mathrm{mmol} / \mathrm{l}$ which it can be considered as life-threatening condition [9] [10]. The prevalence of severe hyponatremia and its non-severe form are estimated $1 \%-4 \%$ and $15 \%$ - 30\% of inpatients, respectively [11]. Hyponatremia represents a serious health problem with significant associated morbidity and mortality.

A study [12] from Iran found that $47 \%$ of pulmonary tuberculosis patient had hypontremia. Another study from Kuwait [13] revealed 22.15\% prevalence of hyponatremia in PTB. No such studies are available in local literature. Prevalence of TB is very high in Pakistan, and we are genetically and geographically different from other population so result of international literature may not be practical in our population. This study will show the prevalence of hyponatremia in PTB, if found to be prevalent clinician will be more focused for management of this electrolyte imbalance which will be beneficial for patients care.

\section{Material and Methods}

This Cross-sectional study was conducted on inpatients at Department of Chest medicine, Jinnah Post graduate Medical Centre (JPMC), Karachi, from August 2017 to August 2018. A total of 96 patients of both genders aged between 18 years and 65 years having pulmonary tuberculosis for two weeks or more duration were included as per non probability consecutive sampling. By using WHO calculator taken prevalence 51\% (12) of pulmonary tuberculosis, margin of error $=10 \%$, confidence interval $=95 \%$, estimated sample size will be at least $n=96$.

Those excluded from the study were either those who failed to give consent or patients having tuberculous meningitis, syndrome of inappropriate Anti diuretic hormone (SIADH), renal failure, active pneumonia, cirrhosis and those who were taking medicines (diuretics, ACEI, ARB during last two weeks) on history.

Study was conducted after approval of institutional ethical review committee. Patients were interviewed in the inpatient department of Chest medicine, JPMC. Written informed consent was obtained from all patients fulfilling inclusion criteria. A structured Performa was used to collect data and the performa filled by the researcher himself. The collected data was transferred to statistical package for the social sciences (SPSS) 20.0 for the statistical analysis. Analyzed by the researcher mean and standard deviation were calculated for age, duration of symptoms and serum sodium $(\mathrm{Na})$ frequency and percentage were calculated for Gender, Diabetes Melitus, hypertension (HTN), Hyponatremia and smoking. Stratification with respect to age, gender, duration of pulmonary TB, DM, HTN and smoking were done. Post stratification Chi square test applied. P-value of $\leq 0.05$ was taken as significant. 


\section{Results}

Ninety six patients with mean age were $40.14 \pm 13.02$ years (ranging $18-65$ years). Predominantly, patients were females 50 (52.08\%). Sixty One patients (63.5\%) were younger than 40 years. Over all Serum Na, Mean \pm SD were 130.53 \pm 6.99 (Ranging 110 - 146). Baseline characteristics are shown in Table 1.

Forty patients (41.66\%) were smokers, 16 (16.7\%) had diabetes mellitus (DM), and $15(15.6 \%)$ had hypertension. Sixty nine (71.87\%) patients had hyponatremia of which majority $45(73.77 \%)$ were noted in age less than 40 years $(\mathrm{p}=$ 0.375). Diabetes mellitus, female gender, smoking, hypertension and duration of disease were not associated with increased risk of hyponatremia having $\mathrm{P}$ Values, $\mathrm{p}=0.082, \mathrm{p}=0.39, \mathrm{p}=0.57, \mathrm{p}=0.20$ and $\mathrm{p}=0.45$ respectively as shown in Table 2.

Table 1. Baseline characteristics of the study population.

\begin{tabular}{cc}
\hline Total number of patients, $\mathrm{n}=$ & 96 \\
\hline Males, n (\%) & $46(47.91 \%)$ \\
Females n (\%) & $50(52.08 \%)$ \\
Age, Mean \pm SD (Range) & $40.14 \pm 13.02(18-65)$ \\
Serum Na, Mean \pm SD (Range) & $130.53 \pm 6.99(110-146)$ \\
$\geq 40$ Years, $\mathrm{n}(\%)$ & $35(36.5 \%)$ \\
$<40$ years, $\mathrm{n}(\%)$ & $61(63.5 \%)$ \\
Hypertension, $\mathrm{n}(\%)$ & $15(15.6 \%)$ \\
Smoking, $\mathrm{n}(\%)$ & $40(41.66 \%)$ \\
Diabetes, $\mathrm{n}(\%)$ & $16(16.7 \%)$ \\
Duration of symptoms & \\
$\geq 6$ Months, $\mathrm{n}(\%)$ & $33(34.37 \%)$ \\
$<6$ Months, $\mathrm{n}(\%)$ & $63(65.63 \%)$
\end{tabular}

Table 2. Stratification of Hyponatremia with respect to age, gender, BMI, Smoking, DM, HTN and duration of symptoms $n=96$.

\begin{tabular}{|c|c|c|c|c|}
\hline \multicolumn{2}{|c|}{$\begin{array}{l}\text { Characteristics with } \\
\text { total number } n=96\end{array}$} & \multirow{2}{*}{$\begin{array}{c}\begin{array}{c}\text { Hyponatremia } \\
\text { Present }\end{array} \\
45(73.77 \%)\end{array}$} & \multirow{2}{*}{$\begin{array}{c}\begin{array}{c}\text { Hyponatremia } \\
\text { absent }\end{array} \\
16(26.22 \%)\end{array}$} & \multirow{3}{*}{$\begin{array}{c}\text { p Value } \\
0.375\end{array}$} \\
\hline \multirow{2}{*}{ AGE (yrs) } & $\leq 4061$ & & & \\
\hline & $>4035$ & $24(68.57 \%)$ & $11(31.43 \%)$ & \\
\hline \multirow{2}{*}{ GENDER } & MALE 46 & $32(69.56 \%)$ & $14(30.44 \%)$ & \multirow{2}{*}{0.399} \\
\hline & FEMALE 50 & $37(74 \%)$ & $13(26 \%)$ & \\
\hline \multirow{2}{*}{ SMOKING } & YES 40 & $29(72.5 \%)$ & $11(27.5 \%)$ & \multirow{2}{*}{0.54} \\
\hline & NO 56 & $40(71.42 \%)$ & $16(28.58 \%)$ & \\
\hline \multirow{2}{*}{$\mathrm{DM}$} & YES 17 & $15(88.24 \%)$ & $2(11.76 \%)$ & \multirow{2}{*}{0.082} \\
\hline & NO 79 & $54(68.35 \%)$ & $25(31.64 \%)$ & \\
\hline \multirow{2}{*}{ HTN } & YES 15 & $9(60 \%)$ & $6(40 \%)$ & \multirow{2}{*}{0.20} \\
\hline & NO 81 & $60(74.08 \%)$ & $21(25.92 \%)$ & \\
\hline \multirow{2}{*}{$\begin{array}{l}\text { Duration of } \\
\text { symptoms }\end{array}$} & $\geq 6$ Months, 33 & $23(68.09 \%)$ & $10(31.90)$ & \multirow{2}{*}{0.45} \\
\hline & $<6$ Months, 63 & $46(73.01 \%)$ & $17(26.99 \%)$ & \\
\hline
\end{tabular}




\section{Discussion}

Tuberculosis (TB) is caused by bacteria (Mycobacterium tuberculosis) that most often affect the lungs. Tuberculosis is curable and preventable. TB occurs in every part of the world. In 2015, the largest number of new TB cases occurred in Asia, with $61 \%$ of new cases, followed by Africa, with $26 \%$ of new cases [1] [2].

Tuberculosis (TB) is one of the major public health problems in Pakistan. Pakistan ranks fifth amongst TB high-burden countries worldwide. It accounts for $61 \%$ of the TB burden in the WHO Eastern Mediterranean Region [2].

Pakistan is also estimated to have the fourth highest prevalence of multidrug-resistant TB (MDR-TB) globally. Tuberculosis (TB) is one of the top 10 causes of death worldwide. In 2015, 10.4 million people fell ill with TB and 1.8 million died from the disease (including 0.4 million among people with HIV). Over $95 \%$ of TB deaths occur in low- and middle-income countries [2]. prevalence of PTB with hyponatremia is around $51 \%$. Diabetes mellitus (DM) is currently known to be one of the risk factors for pulmonary tuberculosis [3].

Various complications have been reported along with PTB. Pulmonary TB is associated with various long term lung complications including lung scarring (fibrosis), bronchiectasis, Chronic Pulmonary aspergillosis (CPA), air way stenosis and Chronic Obstructive Pulmonary Disease (COPD) [6]. The subclinical electrolyte imbalances are customary in cases with PTB. Hyponatremia is considered as one of the most common and important electrolyte abnormalities it must be considered in all seriously ill hospitalized patients [7] [8]. Hyponatremia is defined as depletion in the serum sodium $(\mathrm{Na})$ concentration to a level below $136 \mathrm{mmol} / \mathrm{l}$ and severe hyponatremia defined as serum sodium concentration lesser than $115 \mathrm{mmol} / \mathrm{l}$ which it can be considered as life-threatening condition [9] [10]. The prevalence of severe hyponatremia and its non-severe form are estimated $1 \%-4 \%$ and $15 \%$ - 30\% of inpatients, respectively [11] Hyponatremia represents a serious health problem with significant associated morbidity and mortality.

In a study [12] from Iran found that $47 \%$ of pulmonary tuberculosis patient had hypontremia. Another study from Kuwait [13] revealed 22.15\% prevalence of hyponatremia in PTB. Hongguang C et al. [3] revealed the hyponatremia in PTB was $51 \%$. However in this study hyponatremia was found to be $71.87 \%$ the increase in percentage of hyponatremia is probably due to difference in dietary habits and the patient's selection as in this study inclusion criteria was the admitted patients only. This study will showed the prevalence of hyponatremia in PTB is more compared to other studies; clinician should be more focused for management of this electrolyte imbalance which will be beneficial for patients care.

Ahmed $\mathrm{M}$ et al. [14] found consistent evidence for an increased risk of TB among patients with uncontrolled DM (high-level HbAlc) i.e. 20\% patients had PTB. In a 10 years cohort of 1529 diabetic individuals in Chile, actuarial probability of developing tuberculosis was $24 \%$ in IDDM and $4.8 \%$ in NIDDM [15]. In 
previous literatures, a wide range of DM prevalence from $1.9 \%$ to $35 \%$ has been reported among TB patients [16] [17]. While in our study $16.7 \%$ of PTB were having diabetes the finding is consistent with previous studies.

In our study $63.5 \%$ were younger than 40 years on the contrary of findings with previous studies revealing PTB prevalent in elderly the purposed mechanism of such phenomenon was thought to be reactivation, here in our study we have taken admitted patients with tuberculosis so this is probable difference. In our study almost equal gender ratio while in previous study by Qadeer et al. [18] revealed pulmonary tuberculosis 1.8 times more in men this difference is due to selection criteria as in our study we have taken only inpatients.

Our study showed that pulmonary tuberculosis patients having hyponatremia were patients with younger age, female gender, hypertension, smoking duration of disease and diabetes mellitus but none of them was found to be statistically significant. We selected inpatients, excluded patients in whom potential causes of hyponatremia other than tuberculosis were found. This result led us the assumption that hyponatremia is secondary to PTB.

As we excluded tuberculosis with meningitis and SIADH so prevalence of hyponatremia in our study population may not be true representative of actual burden despite of this fact almost $72 \%$ of our population had hyponatremia only four patients (5.7\% of hyponatremia patients) had severe hyponatremia i.e. serum $\mathrm{Na}<115 \mathrm{mmol} / \mathrm{l}$, Two patients recovered on ATT and sodium replacement while remaining two expired of which one has positive blood cultures as well.

As hyponatremia is significant cause of morbidity and mortality, this study has shown significant relation hyponatremia with PTB. Clinicians should take care of this important electrolyte abnormality while managing PTB.

There are limitations of the study, firstly it is a single centered study with small sample size, and second no questionnaire with internal or external validation used but simple Performa was to collect data. Multicentre study with large population and data on validated questionnaire is needed to assess the electrolyte imbalance with PTB.

\section{Conclusion}

Hyponatremia is associated with pulmonary tuberculosis in almost two thirds of patients which is slightly more common in female gender, younger age or in patients who had history of diabetes, hypertension and smoking. Managing hyponatremia is necessary in pulmonary tuberculosis.

\section{What Is Already Known?}

High burden of tuberculosis in Pakistan.

Association of hyponatremia with pulmonary tuberculosis.

\section{What Is New Here?}

High prevalence of hyponatremia in our pulmonary tuberculosis patients. 
Relative more hyponatremia in female gender and younger ages.

\section{Acknowledgements}

Authors acknowledge their patients for participating in study by giving consent.

\section{Authors' Contribution}

Afshan Nisar, Amanullah Lail: Concept of study, designed the work, wrote the manuscript including the initial draft.

Syed Abdul Waheed, Darkhshan Nisar interviewed the patients, collected the data and analysis.

Nausheen Siafullah and Ghulamullah Lail has contributed with expert knowledge, discussions reviewed and critically revised the draft into final version. All authors have read and agreed to the final manuscript.

\section{Conflicts of Interest}

Authors have no conflicts of interests. We have not received any research grant. We have not used any new pharmacological agent in our project. Written informed consent was taken.

\section{References}

[1] Chakaya, J., Kirenga, B. and Getahun, H. (2016) Long Term Complications after Completion of Pulmonary Tuberculosis Treatment: A Quest for a Public Health Approach. Journal of Clinical Tuberculosis and Other Mycobacterial Diseases, 3, 10-12. https://doi.org/10.1016/j.jctube.2016.03.001

[2] Anderson, L., Dias, H.M., Falzon, D., Floyd, K., Baena, I.G., Gilpin, C., et al. (2016) Global Tuberculosis Report. World Health Organization, Switzerland.

[3] Hongguang, C., Min, L., Shiwen, J., et al. (2015) Impact of Diabetes on Clinical Presentation and Treatment Outcome of Pulmonary Tuberculosis in Beijing. Epidemiology \& Infection, 143, 150-156. https://doi.org/10.1017/S095026881400079X

[4] Griffith, D.E., Girard, W.M. and Wallace Jr., R.J. (1993) Clinical Features of Pulmonary Disease Caused by Rapidly Growing Mycobacteria. An Analysis of $154 \mathrm{~Pa}-$ tients. American Review of Respiratory Disease, 147, 1271-1278.

[5] Uplekar, M., Weil, D., Lonnroth, K., Jaramillo, E., Lienhardt, C., Dias, H.M., et al. (2015) WHO's Global TB Programme. WHO's End TB Strategy. The Lancet, $\mathbf{3 8 5}$ 1799-1801. https://doi.org/10.1016/S0140-6736(15)60570-0

[6] Shah, M. and Reed, C. (2014) Complications of Tuberculosis. Current Opinion in Infectious Diseases, 27, 403-410. https://doi.org/10.1097/QCO.0000000000000090

[7] Upadhyay, A., Jaber, B.L. and Madias, N.E. (2006) Incidence and Prevalence of Hyponatremia. The American Journal of Medicine, 119, S30-S35. https://doi.org/10.1016/j.amjmed.2006.05.005

[8] Lee, P. and Ho, K.K. (2010) Hyponatremia in Pulmonary TB: Evidence of Ectopic Antidiuretic Hormone Production. Chest, 137, 207-208. https://doi.org/10.1378/chest.09-0405

[9] Adrogue, H.J. and Madias, N.E. (2000) Hyponatremia. The New England Journal of Medicine, 342, 1581-1589. https://doi.org/10.1056/NEJM200005253422107

[10] Nzerue, C.M., Baffoe-Bonnie, H., You, W., Falana, B. and Dai, S. (2003) Predictors 
of Outcome in Hospitalized Patients with Severe Hyponatremia. Journal of the National Medical Association, 95, 335-343.

[11] Laczi, F. (2008) Etiology, Diagnostics and Therapy of Hyponatremias. Orvosi Hetilap, 149, 1347-1354. https://doi.org/10.1556/OH.2008.28409

[12] Jafari, N.J., Izadi, M., Sarrafzadeh, F., Heidari, A., Ranjbar, R. and Sabur, A. (2013) Hyponatremia Due to Pulmonary Tuberculosis: Review of 200 Cases. Nephro-Urology Monthly, 5, 687-691. https://doi.org/10.5812/numonthly.7091

[13] Abal, A.T., Jayakrishnan, B., Parwer, S., El Shamy, A.S., Khadadah, M., Ayed, A., et al. (2005) Demographic Pattern and Clinical Characteristics of Patients with SmearPositive Pulmonary Tuberculosis in Kuwait. Medical Principles and Practice, 14, 306-312. https://doi.org/10.1159/000086927

[14] Ahmed, M., Omer, I., Osman, S.M. and Ahmed-Abakur, E.H. (2017) Association between Pulmonary Tuberculosis and Type 2 Diabetes in Sudanese Patients. International Journal of Mycobacteriology, 6, 97-101. https://doi.org/10.4103/ijmy.ijmy_13_17

[15] Olmos, P., Donoso, J., Rojas, N., Landeros, P., Schurmann, R., Retamal, G., Meza, M. and Martinez, C. (1989) Tuberculosis and Diabetes Mellitus: A Longitudinal-Retrospective Study in a Teaching Hospital. Revista Medica de Chile, 117, 979-983.

[16] Dooley, K.E. and Chaisson, R.E. (2009) Tuberculosis and Diabetes Mellitus: Convergence of Two Epidemics. The Lancet Infectious Diseases, 9, 737-746. https://doi.org/10.1016/S1473-3099(09)70282-8

[17] Siddiqui, A.N., Khayyam, K.U. and Sharma, M. (2016) Effect of Diabetes Mellitus on Tuberculosis Treatment Outcome and Adverse Reactions in Patients Receiving Directly Observed Treatment Strategy in India: A Prospective Study. BioMed Research International, 2016, Article ID: 7273935. https://doi.org/10.1155/2016/7273935

[18] Qadeer, E., Fatima, R., Yaqoob, A., Tahseen, S., Haq, M.U., Ghafoor, A., Asif, M., Straetemans, M. and Tiemersma, E.W. (2016) Population Based National Tuberculosis Prevalence Survey among Adults (>15 Years) in Pakistan, 2010-2011. PLoS ONE, 11, e0148293. https://doi.org/10.1371/journal.pone.0148293 